\title{
Role of matrix metalloproteinases in the acquisition and reconsolidation of cocaine-induced conditioned place preference
}

\author{
Travis E. Brown, ${ }^{1}$ Melissa R. Forquer, ${ }^{1}$ Davelle L. Cocking, ${ }^{2}$ Heiko T. Jansen, ${ }^{1}$ \\ Joseph W. Harding ${ }^{1}$ and Barbara A. Sorg ${ }^{1,3}$ \\ ${ }^{7}$ Alcohol and Drug Abuse Research Program and Program in Neuroscience, Department of Veterinary and Comparative Anatomy, \\ Pharmacology and Physiology, Washington State University, Pullman, Washington 99164-6520, USA; ${ }^{2}$ Program in \\ Pharmacology/Toxicology, Washington State University, Pullman, Washington 99164-6520, USA
}

\begin{abstract}
Persistent drug seeking/taking behavior involves the consolidation of memory. With each drug use, the memory may be reactivated and reconsolidated to maintain the original memory. During reactivation, the memory may become labile and susceptible to disruption; thus, molecules involved in plasticity should influence acquisition and/or reconsolidation. Recently, matrix metalloproteinases (MMPs) have been shown to influence neuronal plasticity, presumably by their regulation of extracellular matrix (ECM) molecules involved in synaptic reorganization during learning. We hypothesized that inhibition of MMP activity would impair the acquisition and/or reconsolidation of cocaine-conditioned place preference (CPP) in rats. Intracerebral ventricular (i.c.v.) microinjection of a broad spectrum MMP inhibitor, FN-439, prior to cocaine training suppressed acquisition of CPP and attenuated cocaine-primed reinstatement in extinguished animals. In a separate experiment, the cocaine memory was reactivated on two consecutive days with a cocaine priming injection. On these two days, artificial cerebral spinal fluid (aCSF) or FN-439 was administered either $30 \mathrm{~min}$ prior to or $1 \mathrm{~min}$ after cocaine-primed reinstatement sessions. Infusion of FN-439 partially impaired retrieval of the cocaine-associated context when given 30 min prior to cocaine. In both groups, however, FN-439 suppressed reinstatement compared with controls on the third consecutive test for cocaine-primed reinstatement, when no FN-439 was given. Control experiments demonstrated that two injections of FN-439 + cocaine given in the home cage, or of FN-439 + saline priming injections in the CPP chambers did not disrupt subsequent cocaine-primed reinstatement. These results show for the first time that (1) MMPs play a critical role in acquisition and reconsolidation of cocaine-induced CPP, and (2) rats demonstrate apparent disruption of reconsolidation by an MMP inhibitor after extinction and while they are under the influence of cocaine during reinstatement.
\end{abstract}

The process of drug addiction exploits learning and memory systems (O’Brien et al. 1992; Bonci and Malenka 1999; Thomas et al. 2000; Wise 2000; Hyman 2005), and morphological changes in neurons have been observed after drug exposure (Robinson and Kolb 1997, 1999, 2004; Robinson et al. 2001). However, only a relative handful of studies on drug abuse have examined changes in structural molecules that alter morphology, such as cytoskeletal and cell adhesion proteins (Fosnaugh et al. 1995; Kodama et al. 1998; Tan et al. 2000; Brenz Verca et al. 2001; Freeman et al. 2002, Klebaur et al. 2002; Ujike 2002; Fujiyama et al. 2003; Mackowiak et al. 2005).

The present work focused on molecules that alter neuronal morphology by influencing the extracellular matrix (ECM). The ECM is a meshwork of extracellular proteins found in all tissues, including the brain, and is concentrated in the synaptic cleft. A major regulator of the ECM is a family of zinc-dependent endopeptidases called matrix metalloproteinases (MMPs) (Massova et al. 1998; McCawley and Matrisian 2001; Somerville et al. 2003; Crocker et al. 2004). Released from neurons and glia as zymogens, MMPs become activated once outside the cell and have been implicated in neural plasticity because they degrade the ECM to allow for synapse restructuring (Dzwonek et al. 2004;

\footnotetext{
${ }^{3}$ Corresponding author.
}

E-mail sorg@vetmed.wsu.edu; fax (509) 335-4650.

Article is online at http://www.learnmem.org/cgi/doi/10.1101//m.476207.
Wright and Harding 2004). Meighan et al. (2006) have employed a broad-spectrum inhibitor of MMP activity to demonstrate a critical role for MMPs, including MMP-3 and MMP-9, in the acquisition of spatial learning and long-term potentiation (LTP), and Nagy et al. (2006) have also shown a role for MMP-9 in learning and LTP. Because of the reliance of drug-induced behaviors on learning and memory processes, one goal of the present work was to test whether an inhibitor of MMP activity would also impair the acquisition of cocaine-induced conditioned place preference $(\mathrm{CPP})$ behavior in rats.

Recent evidence supports the possibility that recall or "reactivation" of consolidated memories causes them to again become labile and susceptible to disruption for a period of time after reactivation; thus, the reconsolidation of a memory can be disrupted (Misanin et al. 1968; Nader et al. 2000; Sara 2000; Nader 2003; Debiec et al. 2006). Very recent studies have demonstrated disruption of reconsolidation of cocaine- or morphineassociated memories. Lee et al. $(2005,2006)$ showed that an antisense oligodeoxynucleotide (ODN) for the transcription factor Zif268 attenuated cocaine-seeking behavior in self-administering rats. Miller and Marshall (2005) and Valjent et al. (2006) demonstrated disruption of reconsolidation of a cocaine-associated context by a mitogen-activated protein kinase kinase (MEK) inhibitor. Milekic et al. (2006) found that protein synthesis inhibition disrupted reconsolidation of a morphine-associated context, although this effect was not observed by Yim et al. (2006). 
Bernardi et al. (2006) demonstrated disruption of cocaineinduced CPP with propranolol treatment given just after reactivation of the cocaine-associated memory.

Several, but not all, of these studies examined drug-seeking behavior in the absence of the drug itself. However, reinstatement of cocaine-seeking behavior also occurs after drug priming (de Wit and Stewart 1981; Shaham et al. 2003), and the drug itself triggers craving in human addicts (Ludwig et al. 1974; Jaffe et al. 1989). Thus, we also wished to test whether MMPs were involved in the reconsolidation of the cocaine-associated memory and whether the expression of CPP could be disrupted while rats were under the influence of cocaine during a test for cocaine-primed reinstatement.

\section{Results}

\section{MMP activity assay and in situ zymography}

To determine the effectiveness of FN-439 to inhibit MMP-9, a gelatinase that has previously been shown to influence spatial memory (Meighan et al. 2006; Nagy et al. 2006), we first conducted an in vitro enzyme assay using a purified MMP-9 catalytic domain. Figure $1 \mathrm{~A}$ shows that the $\mathrm{IC}_{50}$ for MMP-9 activity by FN-439 was $223 \mu \mathrm{M}$ in this assay.

We next tested the ability of FN-439 to inhibit MMP activity in an in vitro assay using dorsal hippocampal tissue. We chose to use this tissue because previous gel zymography in our laboratory indicated that basal levels of MMP-2 and MMP-9 (the gelatinases) are high in this brain region. Figure $1 \mathrm{~B}$ shows the results from in situ inhibition of MMP activity by FN-439 in the hippocampus. The $\mathrm{IC}_{50}$ for inhibition of MMP-mediated degradation of a broad MMP substrate by FN-439 was $3.9 \mathrm{mM}$. Reported $\mathrm{IC}_{50}$ values for some MMPs range from $1-150 \mu \mathrm{M}$ in non-brain preparations (Odake et al. 1994). However, several MMPs are present in the
A
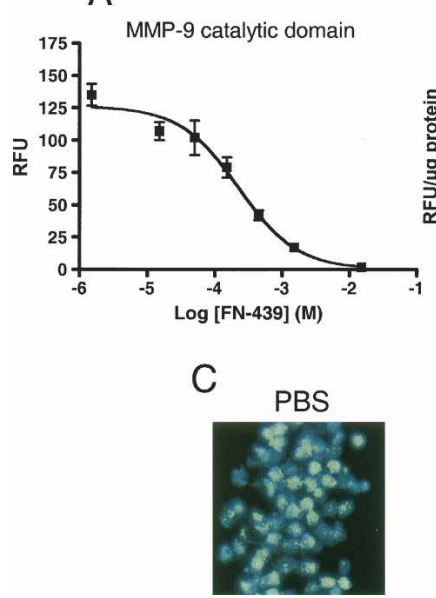

B

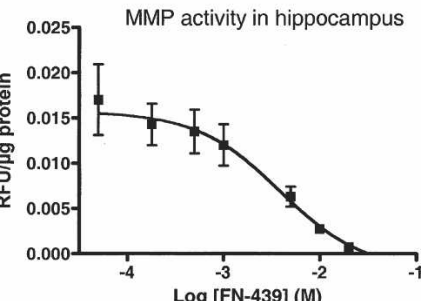

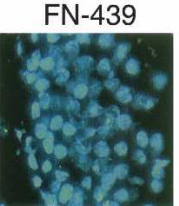

Figure 1. MMP enzyme activity and inhibition by $\mathrm{FN}-439$. $(A)$ Inhibition of MMP-9 catalytic domain-mediated activity and inhibition by FN439. Data are mean \pm SEM of relative fluorescence units (RFU). $N=3$ per dose. The $\mathrm{IC}_{50}$ is $223 \mu \mathrm{M}$. (B) Effect of FN-439 on total MMP activity in dorsal hippocampal tissue. Hippocampal tissue was chosen because it expresses relatively high levels of MMP-2 and MMP-9 (the gelatinases tested in $C$, below). Data are mean \pm SEM of RFU, normalized for protein content. $\mathrm{N}=3-6$ per dose. The $\mathrm{IC}_{50}$ is $3.9 \mathrm{mM}$. (C) In situ zymography demonstrating basal gelatinase activity by MMP-2 and MMP-9 in the dentate gyrus in the presence of PBS (left panel) and in the presence of FN-439 (right panel). MMP activity is indicated by green fluorescence, and nuclei are indicated by blue fluorescence. Note the similar appearance of the cell nuclei between control and FN-treated sections, indicating a lack of overt cellular toxicity. The basal activity of MMP-2 and MMP-9 was not detectable after FN-439 treatment. brain and cleave the nonspecific substrate, and not all of these MMPs are inhibited as effectively by FN-439.

To more specifically examine the ability of FN-439 to inhibit activity of the gelatinases in hippocampal tissue, including MMP9, we exposed hippocampal tissue to $14.3 \mathrm{mM}$ FN-439 to qualitatively determine the extent of suppression of MMP-9 activity in the dentate gyrus. This dose was chosen based on previous reports that the same or a similar concentration of this compound given intracerebral ventricularly (i.c.v.) impaired LTP and blocked the acquisition of a spatial maze task (Reeves et al. 2003; Meighan et al. 2006). Figure 1C illustrates the inhibitory effect of FN-439 on MMP activity (green fluorescence) in situ. There is a similar appearance of the cell nuclei (blue fluorescence) between control and FN-treated sections, indicating a lack of overt cellular toxicity. This finding is similar to what has been reported for other broad MMP inhibitors in the rodent brain (Gu et al. 2005).

\section{Experiment 1: FN-439 infusions given 30 min prior} to training sessions attenuate acquisition of cocaine CPP and subsequent cocaine-primed reinstatement

The results from experiment 1 are shown in Figure 2A-D in which we tested the influence of FN-439 on the acquisition of cocaine CPP. Figure 2A shows the time animals spent on the cocaine-paired side during their test for initial preference, the test for CPP, the last extinction day (other extinction days not shown), and after a cocaine priming injection (cocaine prime). There were no significant differences in the response of animals given only i.p. saline for the training procedure following either artificial cerebral spinal fluid (aCSF) or FN-439; therefore, these two groups were pooled for further analysis. In these animals, no significant effects occurred across training, extinction, or reinstatement. This result in saline-only-treated animals indicates that FN-439 did not have any effects on its own. The results shown in Figure 2 demonstrate that infusion of FN-439 prevented the acquisition of cocaine CPP behavior on the test day compared with aCSF controls and compared within subjects to their initial preference day. On the test for reinstatement after a cocaine priming injection, animals administered FN-439 during the cocaine training days demonstrated a partial and significant attenuation of reinstatement behavior compared with aCSFtreated controls. These findings do not appear to be related to any differences in cocaine metabolism or motor activity, since activity per minute of time spent on the cocaine-paired side was not different between groups on the reinstatement test day $(P<0.23)$ (data not shown). To demonstrate a preference for the cocaine-paired side compared with the saline-paired side, the same data presented in Figure 2A are shown in Figure 2B-D. Saline pooled animals did not demonstrate a preference for the cocaine-paired side (Fig. 2B), while animals given cocaine on the training days along with i.c.v. aCSF showed a preference for the cocaine-paired side on both the test and cocaine prime days (Fig. 2C). When animals were treated with i.c.v. FN-439 on the cocaine training days, however, there was no significant increase in the time spent on the cocaine-paired versus the saline-paired side during the test day, although animals did demonstrate reinstatement after the cocaine prime (Fig. 2D).

\section{Experiment 2: FN-439 infusions given 30 min prior to daily extinction sessions do not impair extinction or subsequent cocaine-primed reinstatement}

Experiment 2 tested whether FN-439 given in the presence of the CPP context during extinction sessions would suppress the rate of extinction of cocaine-induced CPP, and the results are shown in Figure 3. There were no significant differences in the response of animals given i.p. saline only for the training procedure fol- 
lowing either aCSF or FN-439; therefore, these two groups were pooled for further analysis. In these animals, no significant effects occurred across training, extinction, or reinstatement. This result in saline-only-treated animals indicates that FN-439 did not have any effects on its own. The results shown in Figure 3 also indicate that repeated FN-439 administration did not impair extinction learning, and in fact, there may have been a slight acceleration of extinction as demonstrated on extinction days 2

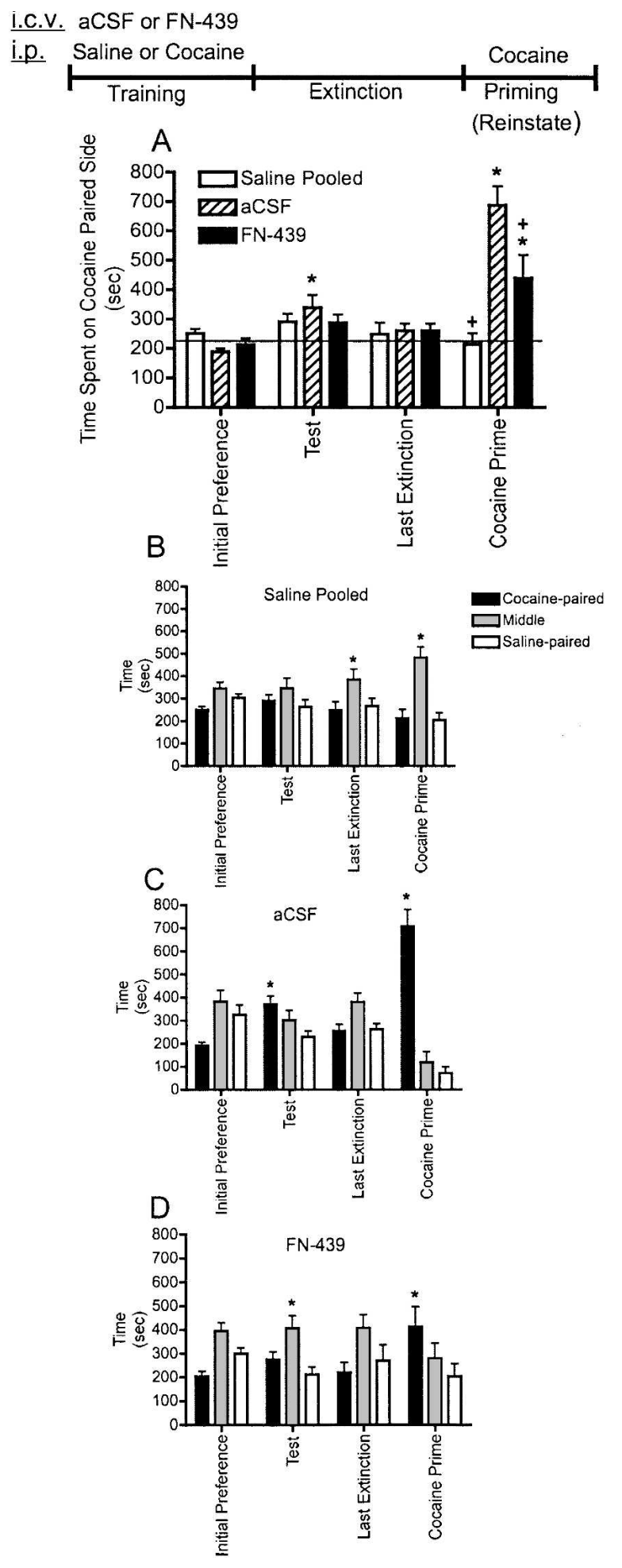

and 6 compared with aCSF controls. When these same animals were given cocaine priming injections on cocaine primes 1-3, both aCSF- and FN-439 treated rats trained with cocaine demonstrated reinstatement. After cocaine prime 2, prior FN-439 treatment produced a significant increase in the degree of place preference behavior compared with aCSF controls. Thus, FN-439 treatment during six consecutive extinction sessions did not impair subsequent reinstatement by cocaine.

\section{Experiment 3: FN-439 infusions given 30 min prior to reinstatement sessions block subsequent cocaine-primed reinstatement}

The results from experiment 3 are shown in Figure 4 in which the effects of FN-439 on reconsolidation were tested. Animals were given the MMP inhibitor, FN-439, on two consecutive days 30 min prior to beginning the cocaine-primed reinstatement sessions. These reinstatement sessions served to reactivate the memory for the cocaine-associated context. Administration of FN-439 prior to cocaine prime 1 produced a decrease in the degree of reinstatement compared with aCSF-treated controls. Although there was still a significant reinstatement compared within subjects to their initial preference day, the results suggest that there may have been a small but significant impairment of retrieval of the memory for the cocaine-associated context. The response was similar on cocaine prime 2 . By cocaine prime 3 , when no microinjection was given, cocaine priming produced reinstatement in controls. However, FN-439 given on the previous two reinstatement days completely blocked reinstatement on cocaine prime 3 . The effect of $\mathrm{FN}-439$ on cocaine prime $1-3$ was not likely due to changes in cocaine metabolism or locomotor activity since there were no treatment effects between control and FN-439 treated rats when activity per minute of time spent on the cocaine-paired side was measured $(P<0.86$ for cocaine prime $1, P<0.87$ for cocaine prime 2 , and $P<0.65$ for cocaine prime 3) (data not shown).

Figure 2. MMP inhibition by FN-439 infusions given 30 min prior to training sessions suppresses acquisition and subsequent reinstatement of cocaine CPP. (A) Comparison among the three treatment groups. Data are mean \pm SEM of time spent in the cocaine-paired compartment. Microinjection (i.c.v.) of aCSF or FN-439 was given on days 1, 3, 5, and 7, $30 \mathrm{~min}$ prior to each cocaine injection on the training days (which are not shown above). Initial preference indicates initial preference for cocainepaired chamber prior to training; test, test day for place preference in cocaine-paired chamber in which no cocaine was administered; last extinction, last extinction day; cocaine prime, cocaine-primed reinstatement using $10 \mathrm{mg} / \mathrm{kg}$ i.p. cocaine. Rats were tested immediately after cocaine injection for reinstatement for a 15-min period. Only the last extinction day is shown for clarity. Pooled saline indicates rats given only saline paired with each CPP compartment and given either aCSF or FN439. Line represents the average of all three groups on the initial preference day. $\mathrm{N}=12$ for pooled saline group; $\mathrm{N}=6$ for aCSF group; $\mathrm{N}=8$ for FN-439 group. There was a significant day effect $\left(F_{(8,184)}=8.73\right.$, $P<0.0001)$ and a significant treatment $\times$ day interaction $\left(F_{(16,184)}=8.08, P<0.0001\right) .{ }^{*} P<0.05$, compared within groups to their initial preference day; $+P<0.05$, compared with aCSF group on the same day. $(B-D)$ Treatment groups are shown separately to indicate time spent in each of the three CPP compartments (cocaine-paired, middle, saline-paired) during each phase of CPP. (B) There was a significant chamber effect $\left(F_{(2,22)}=6.73, P<0.005\right)$ and a significant chamber $\times$ day interaction $\left(F_{(6,66)}=3.08, P<0.010\right)$. (C) There was a significant chamber effect $\left(F_{(2,10)}=5.16, P<0.029\right)$ and a significant chamber $\times$ day interaction $\left(F_{(6,30)}=26.5, P<0.0001\right)$. $(D)$ There was a significant chamber $\times$ day interaction $\left(F_{(6,42)}=2.70, P<0.026\right)$. $\star P<0.05$, compared to saline-paired side on the same day. Note that for clarity, only significant differences from the saline-paired side are indicated in $B-D$. 


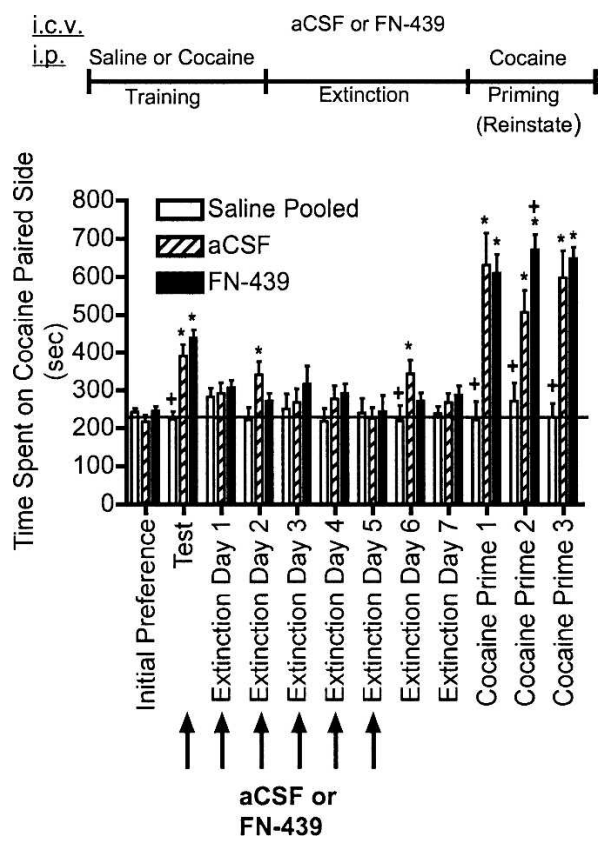

Figure 3. MMP inhibition by $\mathrm{FN}-439$ infusions given $30 \mathrm{~min}$ prior to daily extinction sessions does not suppress extinction or subsequent cocaine-primed reinstatement. Data are mean \pm SEM of time spent in the cocaine-paired compartment. Microinjection (i.c.v.) of aCSF or FN-439 was given $30 \mathrm{~min}$ prior to the test and extinction days $1-5$ (arrows). See Figure 2 for full explanation of terminology. Three consecutive reinstatement days were done (cocaine prime $1-3$ ). $N=10$ for pooled saline group; $\mathrm{N}=9$ for aCSF group; $\mathrm{N}=10$ for $\mathrm{FN}-439$ group. There was a significant treatment effect $\left(F_{(2,26)}=18.37, P<0.0001\right)$, a significant day effect $\left(F_{(11,286)}=26.88, P<0.0001\right)$ and a significant treatment $\times$ day interaction $\left(F_{(22.286)}=8.00, P<0.0001\right)$. ${ }^{*} P<0.05$, compared within groups to their initial preference day; $+P<0.05$, compared with aCSF group on the same day.

\section{Experiment 4: FN-439 infusions given 1 min after completion of reinstatement sessions suppress subsequent cocaine-primed reinstatement}

Figure 5 shows the findings from experiment 4 in which FN-439 infusions were given $1 \mathrm{~min}$ after completing cocaine-primed reinstatement sessions on the first $2 \mathrm{~d}$ of reinstatement testing (cocaine prime 1 and 2). Unlike when FN-439 was administered $30 \mathrm{~min}$ prior to the reinstatement sessions, there was no difference in the time spent on the cocaine-paired side between FN439-treated and aCSF-treated rats on these $2 \mathrm{~d}$. The results indicate that, while rats still demonstrated reinstatement to cocaine prime 3 when no FN-439 was given, there was a significant reduction in the extent of reinstatement compared with aCSF controls.

Experiment 5: FN-439 infusions given 30 min prior to reinstatement sessions in the home cage do not alter subsequent cocaine-primed reinstatement It is possible that the effects of FN-439 described in Figures 4 and 5 were not due to disruption of reconsolidation but to other nonspecific carry-over effects of the drug on cocaine prime 3 . To test for this possibility, experiment 5 examined the effects of administering aCSF or FN-439 in the home cage instead of in the CPP apparatus. In addition, previous studies examining fear conditioning and cocaine- or morphine-seeking behavior indicate that disruption of memory reconsolidation by pharmacological agents requires the presence of the conditioned stimulus (Nader et al. 2000; Lee et al. 2005; Miller and Marshall 2005) or the conditioned stimulus + drug (Milekic et al. 2006; Valjent et al. 2006). Thus, we administered aCSF or FN-439 30 min prior to cocaine in the home cage, in the absence of the CPP context in which they were trained. This design would allow us to determine whether cocaine alone in the absence of the CPP context would render the memory for the cocaine-associated context susceptible to disruption by FN-439. The results shown in Figure 6 indicate that FN-439 + cocaine given on cocaine prime 1 and 2 in the home cage did not impair reinstatement in the CPP box after cocaine prime 3 the next day.

Experiment 6: FN-439 infusions given 30 min prior to saline priming injections do not alter subsequent cocaine-primed reinstatement

An additional experiment examined the effects of FN-439 given 30 min prior to saline priming injections to determine whether the results from Figure 4 demonstrating blockade of cocaineprimed reinstatement were due to nonspecific effects of the i.p. injection procedure given on the first two reinstatement days. The results shown in Figure 7 demonstrate that FN-439 given i.c.v. $30 \mathrm{~min}$ prior to two consecutive days of saline-priming injections did not impair subsequent cocaine-primed reinstatement.

\section{Discussion}

The main findings from this study are (1) inhibition of MMPs by i.c.v. infusion of FN-439 blocks the apparent acquisition of cocaine-induced CPP and suppresses subsequent cocaine-primed
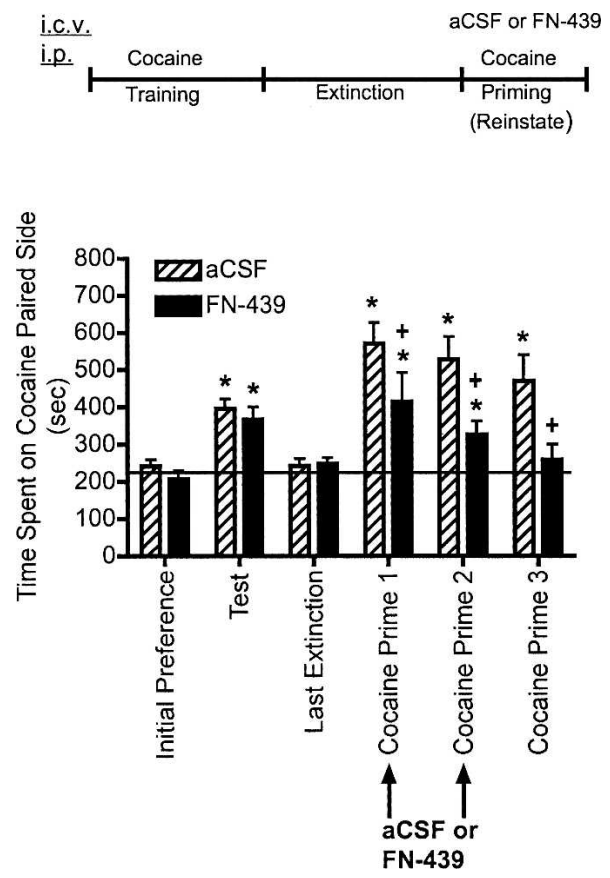

Figure 4. MMP inhibition by FN-439 infusions given 30 min prior to reinstatement sessions blocks reinstatement of cocaine CPP. Data are mean \pm SEM of time spent in the cocaine-paired compartment. Three consecutive reinstatement days were done (cocaine prime 1-3). Microinjection (i.c.v.) of aCSF or FN-439 (indicated by arrows) was given 30 min prior to each of the first two reinstatement days in the CPP cage. See Figure 2 for full explanation of terminology. $\mathrm{N}=11$ for aCSF group; $\mathrm{N}=10$ for $\mathrm{FN}-439$ group. There was a significant treatment effect $\left(F_{(1,19)}=10.30, P<0.004\right)$, a significant day effect $\left(F_{(5,95)}=12.54\right.$, $P<0.0001)$ and a significant treatment $\times$ day interaction $\left(F_{(5,95)}=8.08\right.$, $P<0.029)$. ${ }^{*} P<0.05$, compared within groups to their initial preference day; $+P<0.05$, compared with aCSF group on the same day. 

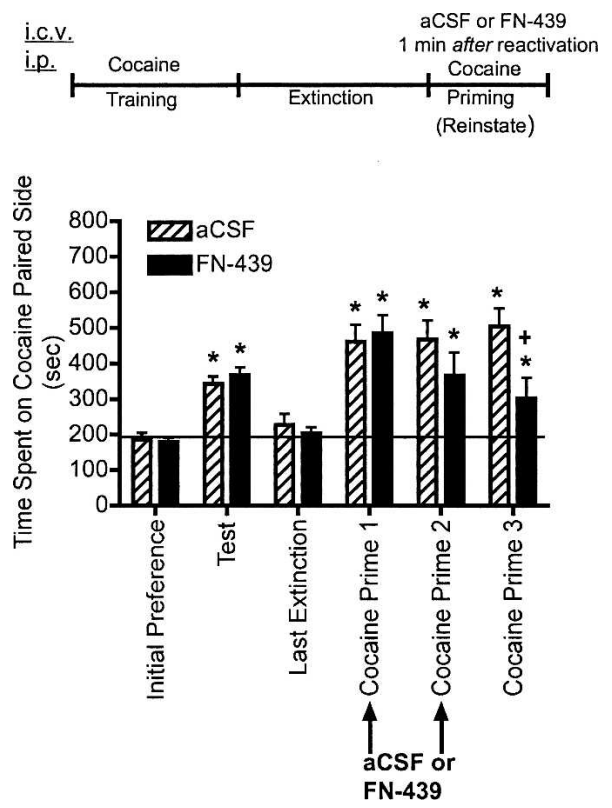

Figure 5. MMP inhibition by FN-439 infusions given $1 \mathrm{~min}$ after reinstatement sessions were completed suppresses reinstatement of cocaine CPP. Data are mean \pm SEM of time spent in the cocaine-paired compartment. Three consecutive reinstatement days were done (cocaine prime 1-3). Microinjection (i.c.v.) of aCSF or FN-439 (indicated by arrows) was given $1 \mathrm{~min}$ after each of the first two reinstatement days in the CPP cage. See Figure 2 for full explanation of terminology. $N=13$ per group. There was a significant treatment $\times$ day effect $\left(F_{(5,120)}=2.88\right.$, $P<0.017) .{ }^{*} P<0.05$, compared within groups to their initial preference day; $+P<0.05$, compared with aCSF group on the same day.

reinstatement of CPP after extinction; (2) inhibition of MMPs by FN-439 appears to impair reconsolidation of the cocaineassociated context even after extinction and while animals are under the influence of cocaine during reinstatement testing; and (3) disruption of reconsolidation by FN-439 infusion appears to require reactivation of the cocaine-associated memory by simultaneous experience of cocaine in the CPP context, although our studies did not rule out whether exposure to the context alone in the presence of FN-439 would attenuate later cocaine-primed reinstatement.

Previous studies examining brain MMPs have focused on the role of these proteins in neuropathology, including traumatic brain injury (Phillips and Reeves 2001), transient ischemia (Rivera et al. 2002), seizures, (Zhang et al. 1998, 2000), amyotrophic lateral sclerosis (Lim et al. 1996), Parkinson's disease (Lorenzl et al. 2002), and deafferentiation (Phillips and Reeves 2001; Reeves et al. 2003; for review, see Dzwonek et al. 2004). However, recent studies have focused on a possible role for MMPs in normal plasticity events such as those involved in learning and memory. Wright et al. (2003) described a correlation between increases in rat hippocampal MMP-9 expression and learning in a water maze. In an extensive set of experiments, Meighan et al. (2006) demonstrated increases in the levels of MMP-3 and MMP-9 and/or their conversion to active enzyme forms during the initial learning phase of rats tested in a water maze. In addition, i.c.v. administration of the MMP inhibitor FN-439 or antisense ODN to MMP-3 and MMP-9 completely prevented water maze learning, while treatment of hippocampal slices with FN439 resulted in a failure to maintain LTP. Nagy et al. (2006) also demonstrated that another broad MMP inhibitor, GM 6001, blocked late-phase LTP induction.

Administration of FN-439 30 min prior to each cocaine injection during the CPP training period blocked the apparent ac- quisition of cocaine-induced CPP, and attenuated later cocaineprimed reinstatement, perhaps by impairing initial acquisition of learning. However, another possibility is that state-dependent learning may have occurred such that cocaine paired with FN439 effects suppressed later retrieval on the test day, when no FN-439 was present. Only some of the retrieval cues were present on this test day (the CPP context but no FN-439 or cocaine), and this may have prevented full retrieval of the memory for the cocaine-associated context and thus expression of CPP. Recovery from transient amnestic effects of other drugs has been addressed in a recent review (Riccio et al. 2006), and it is possible that administration of $\mathrm{FN}-439$ just prior to testing for CPP would have reversed any amnestic effects present. The fact that some reinstatement was observed after a cocaine priming injection several days later may have been due to the cocaine acting as a retrieval enhancer, as was reported for amphetamine by Quartermain et al. (1988).

Administration of FN-439 given 30 min prior to $2 \mathrm{~d}$ of cocaine-primed reinstatement sessions that served as reactivation sessions completely suppressed cocaine-primed reinstatement the next day. However, when FN-439 was given 1 min after the cocaine priming sessions were completed, it produced a partial but significant suppression in cocaine-primed reinstatement the next day. These findings suggest that FN-439 influences a cascade of downstream events within the first $45 \mathrm{~min}$ after i.c.v. administration. The results also suggest that the apparent decreased retrieval we observed when $\mathrm{FN}-439$ was given 30 min prior to the first two reinstatement sessions may have been due to rapid effects on intracellular signaling such that sensory processing of either the cocaine-associated context or the interoceptive cues from cocaine were blunted. Interestingly, in experiment 2 (Fig. 3), no suppression of retrieval was observed when FN-439 was given $30 \mathrm{~min}$ prior to the initial test for CPP, when no cocaine was present.


Figure 6. MMP inhibition by $\mathrm{FN}-439$ infusions given $30 \mathrm{~min}$ prior to reinstatement sessions in the home cage does not alter reinstatement of cocaine CPP. Data are mean \pm SEM of time spent in the cocaine-paired compartment. Three consecutive reinstatement days were done (cocaine prime 1-3), but drugs were administered in the home cage on the first 2 $\mathrm{d}$ instead of in the CPP box. Microinjection (i.c.v.) of aCSF or FN-439 (indicated by arrows) was given 30 min prior to cocaine injection in the home cage or in the CPP cage (cocaine prime 3). See Figure 2 for full explanation of terminology. $\mathrm{N}=10$ for aCSF group; $\mathrm{N}=11$ for $\mathrm{FN}-439$ group. There was a significant day effect $\left(F_{(3,57)}=14.02, P<0.0001\right)$. ${ }^{*} P<0.05$, compared within groups to their initial preference day. 

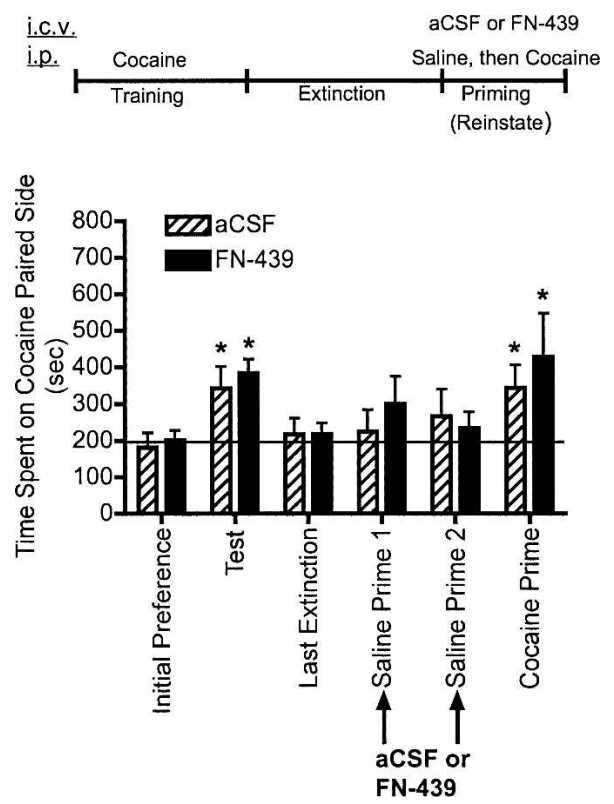

Figure 7. MMP inhibition by $\mathrm{FN}-439$ infusions given $30 \mathrm{~min}$ prior to saline priming injections does not alter subsequent cocaine-primed reinstatement. Data are mean \pm SEM of time spent in the cocaine-paired compartment. Three consecutive reinstatement days were done, but on the first $2 \mathrm{~d}$ only saline injections were given (saline prime 1 and 2). A cocaine injection was given $1 \mathrm{~d}$ later (cocaine prime). Microinjection (i.c.v.) of aCSF or FN-439 (indicated by arrows) was given 30 min prior to saline injections. See Figure 2 for full explanation of terminology. $N=6$ for aCSF group; $N=7$ for FN-439 group. There was a significant day effect $\left(F_{(5,55)}=5.31, P<0.0005\right)$. ${ }^{*} P<0.05$, compared within groups to their initial preference day.

It is not evident which downstream targets are affected by FN-439-mediated inhibition of MMPs. Several components of the ECM may be targeted, including fibronectins, tenascins, laminin, chondroitin sulfate proteoglycan (Stamenkovic 2003), and non-ECM targets important in plasticity such as integrins (Conant et al. 2004; Nagy et al. 2006), cadherins (Lochter et al. 1997), and neural cell adhesion molecules (Stamenkovic 2003; Hubschmann et al. 2005). An additional downstream target of MMPs that is altered after water maze learning is the actinbinding protein, cortactin, which regulates the dendritic cytoskeleton (Meighan et al. 2006). However, it is important to point out that our results from the reconsolidation experiments do not rule out the possibility that FN-439-mediated decreases in cocaine-primed reinstatement were due to state-dependent effects. That is, FN-439 administration may have created a different internal state in the animal during the reconsolidation period, and this state may have been induced independently of its effects on MMP inhibition. If a different internal state was created under the influence of FN-439, then administering FN-439 along with cocaine on the third reinstatement test (cocaine prime 3) may have revealed a level of reinstatement comparable to that of vehicle controls.

Our findings describing the ability to disrupt apparent reconsolidation of a cocaine-associated contextual memory are in accordance with very recent reports examining reconsolidation of cocaine- and morphine-associated memories (Lee et al. 2005; Miller and Marshall 2005; Milekic et al. 2006; Valjent et al. 2006). Lee et al. $(2005,2006)$ demonstrated that infusion of an antisense ODN for Zif268 into the basolateral amygdala (BLA) immediately after reactivation of a cocaine-associated memory attenuated responding (lever pressing) for the previously drug-paired cue. Miller and Marshall (2005) demonstrated that reactivation of the cocaine-associated memory by placement in the CPP chamber in which rats were previously trained with cocaine increased the levels of phosphorylated extracellular signalregulated kinase $1 / 2$ (pERK), ets-like gene-1 (pElk-1), and cAMP response element binding protein (pCREB). Subsequently, they demonstrated that a MEK inhibitor infused into the nucleus accumbens attenuated pERK, pElk-1, and pCREB potentiation only if the cocaine-associated memory was reactivated prior to administration of the MEK inhibitor, and animals given the MEK inhibitor displayed decreased CPP. Subsequently, Valjent et al. (2006) showed that systemic administration of a MEK inhibitor impaired reconsolidation of cocaine- and morphine-associated memories using CPP, but that both the CPP chamber and drug were necessary during re-exposure sessions in order for the MEK inhibitor to disrupt the drug-associated memory. Milekic et al. (2006) also demonstrated that reconsolidation of a morphineassociated memory was disrupted by protein synthesis inhibitors only when rats received a reactivation session with morphine while located inside the CPP chambers. We did not assess whether reactivation using the CPP contextual cues alone (i.e., confinement to the cocaine-paired context without cocaine injection) would enable FN-439 to disrupt later cocaine-primed reinstatement. However, we did find that exposure to cocaine in the home cages instead of in the CPP chambers did not suppress cocaine-primed reinstatement, suggesting that the interoceptive cues of cocaine alone are insufficient for reactivation of the cocaine-associated contextual memory and disruption by FN-439.

The assumption in this interpretation of our data is that state-dependent retrieval allows for cocaine priming injections to promote retrieval of the memory for the cocaine-associated context. Full reactivation of the cocaine-associated contextual memory and thus ability to disrupt it with pharmacological agents may be dependent on all of the drug cues, including interoceptive cues and attributes of the context that might be enhanced by psychostimulants. This line of reasoning suggests that disruption of memory reconsolidation for drugs of abuse may be facilitated by the presence of the training drug because (1) the drug memory may be more completely reactivated, and (2) expression of a competing extinction trace is likely to be minimal during reinstatement. Consistent with the present results, two recent studies have shown that rats or mice do not demonstrate reinstatement even while under the influence of cocaine after treatment with a systemic MEK inhibitor (Valjent et al. 2006) or Zif268 antisense into the BLA (Lee et al. 2006). Lee et al. (2006) showed that cue-induced reinstatement of cocaine-seeking behavior could be disrupted in extinguished rats, and Duvarci et al. (2006) have shown that extinction did not impair the ability to disrupt reconsolidation of a fear memory. Together with these latter studies, our finding that expression of memory for the cocaine-associated context is suppressed in the presence of cocaine may have particular relevance to therapeutic strategies for conditions in which humans continue to take drugs, because drug priming can produce additional craving in addicted individuals (Ludwig et al. 1974; Jaffe et al. 1989).

An alternative explanation for our results from the reconsolidation studies is that FN-439 administration simply impaired memory in general. However, three of our experimental results counter this idea. First, rats given FN-439 infusion in the home cage still demonstrated memory for the cocaine-associated context (Fig. 6). Second, rats administered FN-439 along with saline priming injections failed to suppress cocaine-primed reinstatement the next day (Fig. 7). Third, repeated administration of FN-439 prior to several extinction sessions did not impair cocaine-induced reinstatement for three consecutive days, and in fact, there was a significant elevation of reinstatement on cocaine 
prime 2 (Fig. 3). Thus, the memory for the cocaine-paired side was not impeded even after several pretreatments with FN-439.

The critical brain sites for FN-439-mediated actions remain to be tested. Interestingly, FN-439 infusion did not produce impairment of extinction learning of cocaine-induced CPP. This may be due to the lack of a sufficient dose of FN-439 or to the inability of FN-439 to diffuse to brain sites involved in extinction. Some studies suggest that brain areas involved in consolidation are different from those involved in reconsolidation (Vianna et al. 2001; Kraus et al. 2002; Tronel and Sara 2002; Bahar et al. 2004; Lee et al. 2004; Salinska et al. 2004). However, overlap between these two processes occurring within the same brain area has also been reported (Nader et al. 2000; Eisenberg et al. 2003; Kelly et al. 2003; Koh and Bernstein 2003; Nader 2003; Sangha et al. 2003). Furthermore, the molecules underlying consolidation versus reconsolidation may be dependent on the brain area examined. Given these findings, it is reasonable to consider that MMP inhibition by FN-439 impacts acquisition and reconsolidation processes without affecting extinction learning.

In summary, these studies demonstrate for the first time that MMPs may be involved in learning a cocaine-associated contextual memory, and that reconsolidation of this memory appears to be disrupted by an MMP inhibitor. Further, they demonstrate the ability of an MMP inhibitor to impair expression of memory for a cocaine-associated context after extinction and while the animal is under the influence of the drug. These studies support the notion that the memory and/or retrieval cues for drug-associated contexts can be diminished by pharmacological agents, and the findings may lead to the development of new treatment strategies for human cocaine addicts.

\section{Materials and Methods}

\section{Animal housing and drugs}

Male Sprague-Dawley rats weighing 280-300 g were obtained from Harlan Laboratories. Experiments were conducted according to the National Institutes of Health Guide for the Care and Use of Laboratory Animals, and experimental protocols were approved by the University Animal Care and Use Committee. Animals were housed in groups of two per cage with free access to food and water in a temperature- and humidity-controlled room with a 12-h light cycle. After cannulae implantation, animals were singly housed.

Cocaine hydrochloride was obtained from Sigma Chemical Company and dissolved as the weight of the salt to a final concentration of $12 \mathrm{mg} / \mathrm{mL}$ (training dose) or $10 \mathrm{mg} / \mathrm{mL}$ (reinstatement dose). FN-439 (Odake et al. 1994) was obtained from Calbiochem (FN-439 = MMP inhibitor I) and dissolved in aCSF (5 $\mathrm{mM}$ d-glucose, $2.7 \mathrm{mM} \mathrm{KCl}, 140 \mathrm{mM} \mathrm{NaCl}, 1.2 \mathrm{mM} \mathrm{MgCl}_{2}, 1.4$ $\mathrm{mM} \mathrm{CaCl}_{2}, 0.15 \% \mathrm{PBS}$ ) to a concentration of $14.3 \mathrm{mM}$ for all in vivo studies.

\section{Fluorescence assay for MMP activity measurements}

The in vitro assay to test for MMP-9 activity was done in black 96-well plates according to the manufacturer's instructions from Biomol International L.P. The catalytic domain for MMP-9 was used with the fluorogenic peptide substrate: Mca-Pro-Leu-GlyLeu-Dpa-Ala-Arg- $\mathrm{NH}_{2}$. Samples were preincubated with FN-439 for $30 \mathrm{~min}$ at $37^{\circ} \mathrm{C}$. Subsequently, the fluorogenic peptide substrate was added to the samples and fluorescence was measured at 10-min intervals for $1 \mathrm{~h}$ using a Perkin-Elmer plate reader. For data analysis, slopes were derived from the linear portion of the curves and background slopes were subtracted from all samples. The slopes were normalized as percentages of enzyme activity compared with activity in the absence of inhibitor. IC $_{50}$ values were extrapolated using a sigmoidal curve fit for each sample and averaged using GraphPad Prism.

We next determined the effectiveness of FN-439 inhibition in dorsal hippocampal tissue. Naïve rats were euthanized by de- capitation, and isolated dorsal hippocampi were homogenized at $4^{\circ} \mathrm{C}$ in $500 \mu \mathrm{L}$ of $0.05 \mathrm{M}$ Tris- $\mathrm{HCl}(\mathrm{pH} 7.5)$, containing $0.015 \mathrm{M}$ $\mathrm{NaCl}$ and $10 \mathrm{mM} \mathrm{CaCl}$. The homogenate was centrifuged at $8000 \mathrm{~g}$ for $15 \mathrm{~min}$ at $4^{\circ} \mathrm{C}$. The resulting supernatant was stored at $-80^{\circ} \mathrm{C}$. For the MMP activity assay, we used a modified protocol provided with the Biomol fluorescent assay kit (Biomol Research Laboratories). Briefly, various concentrations of FN-439 were preincubated in a black 96 -well plate for $30 \mathrm{~min}$ at $37^{\circ} \mathrm{C}$ with hippocampal homogenate, after which time the OmniMMP fluorescent substrate peptide was added to each well. Fluorescence was measured every $10 \mathrm{~min}$ for $40 \mathrm{~min}$ at $340 \mathrm{~nm}$ (Em) and $400 \mathrm{~nm}$ (Ex) using a Packard Fusion microplate reader. Slopes were measured by using the readings between 10 and 40 min for analysis. To normalize for protein concentrations, a protein assay was conducted using a BCA protein assay kit (Pierce). The $\mathrm{IC}_{50}$ value was obtained as described above.

\section{In situ zymography}

Experimentally naïve rats were euthanized by decapitation, and brains were frozen by placing them uncovered in the $-80^{\circ} \mathrm{C}$

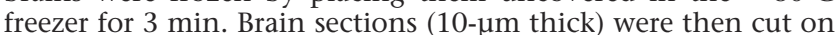
a cryostat and the sections mounted on Superfrost plus slides (VWR International) and stored at $-80^{\circ} \mathrm{C}$ for $\leq 7 \mathrm{~d}$. To determine in situ MMP activity, slides were first warmed to room temperature for $10 \mathrm{~min}$. A well was formed around the tissue sections using a PAP Pen (Ted Pella, Inc). Sections were then preincubated for $3 \mathrm{~h}$ in either PBS ( $\mathrm{pH} 7.4$, control) or $14.3 \mathrm{mM}$ FN-439 dissolved in PBS. The control slides were then incubated for an additional $1 \mathrm{~h}$ with DQ-gelatin-FITC (DQ; Molecular Probes) while the FN-439 slides were incubated for an additional $1 \mathrm{~h}$ with the DQ containing $14.3 \mathrm{mM} \mathrm{FN}-439$. All incubations were performed at $37^{\circ} \mathrm{C}$. Following incubation, the slides were washed in PBS, fixed with $4 \%$ paraformaldehyde in PBS, and cover-slipped with Prolong anti-fade mounting medium containing DAPI (Molecular Probes). Slides were examined on a Zeiss Axioplan 2I microscope (Zeiss, Inc) using epifluorescent illumination and appropriate filter sets for visualizing DQ (FITC) and DAPI (UV) fluorescence. Images were captured at $100-200 \times$ magnification using a Kodak DC290 digital camera (Eastman Kodak Co.) and Photoshop software (Adobe Systems Inc.). Images from control and FN-439-treated sections were collected using the same camera exposure settings and any post-capture manipulations (e.g., background subtraction and brightness/contrast adjustment) utilized identical settings in Photoshop.

\section{Animal surgery and microinjection}

\section{Surgery}

Rats were anesthetized with zyket (ketamine $87 \mathrm{mg} / \mathrm{kg}+$ xylazine $13 \mathrm{mg} / \mathrm{kg}$ ) and placed into a stereotaxic apparatus. For i.c.v. microinjection, a unilateral 26-gauge stainless steel cannulae (Plastics One) was fixed with dental acrylic cement over the lateral ventricle $(-1.0$ from bregma, $\pm 1.5 \mathrm{~mm}$ from midline and -4.0 $\mathrm{mm}$ from skull). Obturators (33 gauge) the length of the guide cannulae were inserted into the cannulae at times other than during microinjection. Rats recovered $1 \mathrm{wk}$ prior to experimentation. At the end of the experiment, all cannulae placements were verified with dye injection into the lateral ventricle.

\section{Microinjection}

Intracranial injections were done using a 33-gauge stainless steel needle connected to PE-20 tubing leading to a 5.0- $\mu \mathrm{L}$ Hamilton syringe. The 33-gauge needles were lowered $1 \mathrm{~mm}$ below the guide cannulae, and a volume of $5.0 \mu \mathrm{L}$ was delivered over a period of 2 min using an infusion pump. The needles were allowed to remain in place for $30 \mathrm{sec}$ following the injection. For experiments 3-6 in which only two microinjections were given on the tests for reinstatement (cocaine or saline prime 1 and 2), a microinjection of saline was always given prior to the first day of test microinjections to adapt the animals to the procedure. 


\section{Conditioned place preference procedure}

All CPP studies were conducted during the same time of day. The proposed studies employed a three-compartment CPP apparatus (Med Associates, Inc.). Each apparatus is made of Plexiglas, with two main compartments measuring $28 \times 21 \times 21 \mathrm{~cm}$ and a smaller central compartment measuring $12 \times 21 \times 21 \mathrm{~cm}$. The black compartment has a wire mesh floor (1-cm squares), and the white compartment has metal rods spaced $1 \mathrm{~cm}$ apart. The central gray compartment has a smooth, gray floor. In addition, a $15-\mathrm{W}$ bulb is placed $8 \mathrm{~cm}$ above the black compartment to offset initial preference for this side of the apparatus. The system is automated (using infrared photocell beams) to allow for assessment of locomotor activity and side preference for each compartment.

Rats were preconditioned for the cocaine place preference procedure as follows. Animals were placed into the central compartment of one of eight boxes. The animals were free to explore all three compartments for a 15-min period. The time spent in each compartment was analyzed by automated software. All compartments were cleaned and wiped dry between animal runs. Two preconditioning days were conducted, and the second day was used for determining preference (referred to as initial preference day), because on the first day, the apparatus is novel to the rat.

We administered cocaine on the nonpreferred side. The conditioning stage began $1 \mathrm{~d}$ after the last preconditioning test. A cocaine or saline injection was given each day. Animals received four saline ( $1 \mathrm{~mL} / \mathrm{kg}$, i.p.) and four cocaine (12 mg/kg, i.p.) pairings in an alternating fashion and were confined to the assigned compartment for a 30-min period. Thus, a total of $8 \mathrm{~d}$ of training was done. In some cases (experiments 1 and 2 described below), certain groups of rats were given only saline prior to confinement in alternating compartments for $8 \mathrm{~d}$.

The test day for cocaine-induced CPP was done $1 \mathrm{~d}$ after the last conditioning (training) day. Rats were tested in the drug-free state. Each animal was placed into the central compartment and had free access to all compartments over a 15 -min test period.

To allow for extinction of conditioned place preference behavior, rats were placed into the central compartment for $15 \mathrm{~min}$ each day (Mueller and Stewart 2000) and monitored for time spent in each compartment as described above. This procedure took place once per day and continued until rats reached a criterion of no significant difference in the time spent on the cocaine-paired side when compared with the initial preference day (group means compared using a one-way, repeated-measures ANOVA). The exception to this was experiment 2, in which rats were infused with aCSF or FN-439 on the test day and on each day through extinction day 5. Animals' place preference was significantly extinguished by day 5 , but extinction was continued in the absence of prior infusion to test whether they would respond similarly without infusion. Reinstatement testing commenced the day after the last extinction day. The cocainepriming dose was $10 \mathrm{mg} / \mathrm{kg}$, i.p. For saline priming injections (experiment 6 only), animals were given $1 \mathrm{~mL} / \mathrm{kg}$. Immediately after the priming injection, the animal was placed into the central compartment and had free access to all compartments over a 15-min period.

\section{Experimental procedures}

In experiment 1 , we tested whether the MMP inhibitor would impair acquisition of cocaine CPP. Four groups of animals were tested (i.c.v. aCSF + i.p. saline only; FN-439 + saline only; aCSF + cocaine alternating with saline; FN-439 + cocaine alternating with saline). Either aCSF $(5 \mu \mathrm{L})$ or FN-439 $(35 \mu \mathrm{g}$ in $5 \mu \mathrm{L}$ [14.3 mM]) was microinjected i.c.v. $30 \mathrm{~min}$ prior to each cocainepaired conditioning day. Therefore, the animals received a total of four FN-439 microinjections during conditioning. After training, all animals underwent testing, extinction, and reinstatement as described above.

Experiment 2 was conducted to determine whether FN-439 given $30 \mathrm{~min}$ prior to extinction sessions would alter the rate of extinction of CPP behavior. We conducted extinction sessions prior to cocaine-primed reinstatement because we wished to model self-administration studies in which several extinction sessions are followed by cocaine-primed reinstatement (for examples, see De Vries et al. 1998; McFarland et al. 2003; Schmidt and Pierce 2006). Four groups of animals underwent preconditioning and conditioning sessions (i.c.v. aCSF + i.p. saline only; FN-439 + saline only; aCSF + cocaine alternating with saline; FN439 + cocaine alternating with saline). Animals were given an i.c.v. microinjection of aCSF $(5 \mu \mathrm{L})$ or FN-439 $(35 \mu \mathrm{g}$ in $5 \mu \mathrm{L}) 30$ min prior to the test for CPP (the first extinction day where no cocaine was given) and prior to extinction days $1-5$. Therefore, animals received a total of six microinjections. Animals then underwent two additional days of extinction followed by three consecutive days of cocaine-primed reinstatement in which only cocaine was administered with no microinjections.

In experiment 3, we tested whether the MMP inhibitor would impair reconsolidation of the memory for the cocaineassociated context if this compound was given prior to reactivation sessions, which consisted of cocaine-primed reinstatement. Animals underwent preconditioning, conditioning, testing, and extinction as described above, but $30 \mathrm{~min}$ prior to cocaineprimed reinstatement, the animals were microinjected i.c.v. with aCSF $(5 \mu \mathrm{L})$ or FN-439 (35 $\mu \mathrm{g}$ in $5 \mu \mathrm{L})$ followed by cocaine and placed immediately into the central compartment of their CPP box (cocaine prime 1). The next day, the procedure from the first day of reinstatement was repeated (cocaine prime 2 ). The following day, animals were tested for cocaine-primed reinstatement without any prior microinjection of aCSF or FN-439 in their CPP box (cocaine prime 3). We chose to administer aCSF or FN-439 for two consecutive days during reinstatement testing instead of just $1 \mathrm{~d}$ as reported by others (Lee et al. 2005; Miller and Marshall 2005) because pilot studies indicated only a partial reduction in cocaine-primed reinstatement on the following day after only a single FN-439 treatment.

Because the administration of FN-439 appeared to partially impair the recall of CPP behavior on the first test for reinstatement in experiment 3 , experiment 4 was conducted to determine whether FN-439 microinjection could be given 1 min after completion of each of the two cocaine-primed reinstatement sessions (cocaine prime 1 and 2 ). This experiment was identical to experiment 3 except that FN-439 was given $1 \mathrm{~min}$ after the cocaine-primed reinstatement session was completed. As in experiment 3 , rats were then given a cocaine-primed reinstatement $1 \mathrm{~d}$ later in the absence of aCSF or FN-439 microinjection.

Experiment 5 was identical to experiment 3 with exception of the cage location where FN-439 infusion and cocaine injection took place on the first two reinstatement days. In experiment 5 , animals were given aCSF or FN-439 and cocaine in the home cage instead of in the CPP apparatus for the first $2 \mathrm{~d}$; this treatment in the home cage replaced cocaine prime 1 and 2 in the CPP apparatus. This was done to determine whether reactivation of the memory for the cocaine-associated context by cocaine in the CPP context was necessary for the ability of FN-439 to disrupt reconsolidation. Animals underwent preconditioning, conditioning, testing, and extinction as described above but $30 \mathrm{~min}$ prior to a cocaine injection in the home cage $(10 \mathrm{mg} / \mathrm{kg}$, i.p.), animals were microinjected i.c.v. with aCSF $(5 \mu \mathrm{L})$ or FN-439 (35 $\mu \mathrm{g}$ in $5 \mu \mathrm{L})$ in their home cage. The next day, the procedure from the first day was repeated. The following day, animals were tested for cocaineprimed reinstatement in their CPP box without any prior microinjection of aCSF or FN-439, exactly as described for cocaine prime 3 in experiments 3 and 4 above.

Experiment 6 was also identical to experiment 3 except that saline rather than cocaine priming injections were given in the CPP context on the first two "reinstatement" days (saline prime 1 and 2). Animals were given either aCSF or FN-439 30 min prior to saline prime 1 and 2, and the next day, a cocaine injection was given in the absence of any microinjection (cocaine prime). This experiment was done to determine whether the results from cocaine priming injections were due to nonspecific effects or to the conditioned effects of the i.p. injection procedure.

\section{Data analysis}

For analysis of CPP behavior, the time spent on the cocainepaired side and the number of photocell beam interruptions (to 
assess general activity levels) is reported. All data were analyzed using a two-way, repeated-measures ANOVA (aCSF vs. FN-439 treatment as the between-subjects measure; day as the withinsubjects measure), followed by a Fischer's least significant difference (LSD) test in the case of a significant interaction $(P<0.05)$. For Figure 2B-D, a two-way, repeated-measures ANOVA (chamber by day) was conducted and followed by an LSD test in the case of a significant interaction. All group sizes and significant differences are reported in the figure legends.

\section{Acknowledgments}

We thank Drs. John W. Wright, Starla Meighan, and Pete Meighan for helpful discussions and Ms. Jenny Baylon for assistance with the manuscript. This work was supported by National Institute on Drug Abuse Grant DA 14915 and by Washington State Initiative 171.

\section{References}

Bahar, A., Dorfman, N., and Dudai, Y. 2004. Amygdalar circuits required for either consolidation or extinction of taste aversion memory are not required for reconsolidation. Eur. J. Neurosci. 19: 1115-1118.

Bernardi, R.E., Lattal, K.M., and Berger, S.P. 2006. Postretrieval propranolol disrupts a cocaine conditioned place preference. Neuroreport 17: 1443-1447.

Bonci, A. and Malenka, R.C. 1999. Properties and plasticity of excitatory synapses on dopaminergic and GABAergic cells in the ventral tegmental area. J. Neurosci. 19: 3723-3730.

Brenz Verca, M.S., Widmer, D.A., Wagner, G.C., and Dreyer, J. 2001. Cocaine-induced expression of the tetraspanin CD81 and its relation to hypothalamic function. Mol. Cell. Neurosci. 17: 303-316.

Conant, K., St Hillaire, C., Nagase, H., Visse, R., Gary, D., Haughey, N., Anderson, C., Turchan, J., and Nath, A. 2004. Matrix metalloproteinase 1 interacts with neuronal integrins and stimulates dephosphorylation of Akt. J. Biol. Chem. 279: 8056-8062.

Crocker, S.J., Pagenstecher, A., and Campbell, I.L. 2004. The TIMPs tango with MMPs and more in the central nervous system. $J$. Neurosci. Res. 75: 1-11.

Debiec, J., Doyere, V., Nader, K., and Ledoux, J.E. 2006. Directly reactivated, but not indirectly reactivated, memories undergo reconsolidation in the amygdala. Proc. Natl. Acad. Sci. 103: 3428-3433.

De Vries, T.J., Schoffelmeer, N.A.N.M., Binnekade, R., Mulder, A.H., and Vandershuren, L.J. 1998. Drug-induced reinstatement of heroin- and cocaine-seeking behaviour following long-term extinction is associated with expression of behavioural sensitization. Eur. J. Neurosci. 10: $3565-3571$.

de Wit, H. and Stewart, J. 1981. Reinstatement of cocaine-reinforced responding in the rat. Psychopharmacology 75: 134-143.

Duvarci, S., Mamou, C.B., and Nader, K. 2006. Extinction is not a sufficient condition to prevent fear memories from undergoing reconsolidation in the basolateral amygdala. Eur. J. Neurosci. 24: 249-260.

Dzwonek, J., Rylski, M., and Kaczmarek, L. 2004. Matrix metalloproteinases and their endogenous inhibitors in neuronal physiology of the adult brain. FEBS Lett. 567: 129-135.

Eisenberg, M., Kobilo, T., Berman, D.E., and Dudai, Y. 2003. Stability of retrieved memory: inverse correlation with trace dominance. Science 301: 1102-1104.

Fosnaugh, J.S., Bhat, R.V., Yamagata, K., Worley, P.F., and Baraban, J.M. 1995. Activation of arc, a putative "effector" immediate early gene, by cocaine in rat brain. J. Neurochem. 64: 2377-2380.

Freeman, W.M., Brebner, K., Patel, K.M., Lynch, W.J., Roberts, D.C., and Vrana, K.E. 2002. Repeated cocaine self-administration causes multiple changes in rat frontal cortex gene expression. Neurochem. Res. 27: 1181-1192.

Fujiyama, K., Kajii, Y., Hiraoka, S., and Nishikawa, T. 2003. Differential regulation by stimulants of neocortical expression of mrt1, arc, and homer1a mRNA in the rats treated with repeated methamphetamine. Synapse 49: 143-149.

Gu, Z., Cui, J., Brown, S., Fridman, R., Mobashery, S., Strongin, A.Y., and Lipton, S.A. 2005. A highly specific inhibitor of matrix metalloproteinase-9 rescues laminin from proteolysis and neurons from apoptosis in transient focal cerebral ischemia. J. Neurosci. 25: 6401-6408.

Hubschmann, M.V., Skladchikova, G., Bock, E., and Berezin, V. 2005. Neural cell adhesion molecule function is regulated by metalloproteinase-mediated ectodomain release. J. Neurosci. Res. 80: $826-837$.
Hyman, S.E. 2005. Addiction: A disease of learning and memory. Am. J. Psychiatry 162: 1414-1422.

Jaffe, J.H., Cascella, N.G., Kumor, K.M., and Sherer, M.A. 1989. Cocaine-induced cocaine craving. Psychopharmacology 97: 59-64.

Kelly, A., Laroche, S., and Davis, S. 2003. Activation of mitogen-activated protein kinase/extracellular signal-regulated kinase in hippocampal circuitry is required for consolidation and reconsolidation of recognition memory. J. Neurosci. 23: 5354-5360.

Klebaur, J.E., Ostrander, M.M., Norton, C.S., Watson, S.J., Akil, H., and Robinson, T.E. 2002. The ability of amphetamine to evoke arc (Arg 3.1) mRNA expression in the caudate, nucleus accumbens and neocortex is modulated by environmental context. Brain Res. 930: $30-36$.

Kodama, M., Akiyama, K., Ujike, H., Shimizu, Y., Tanaka, Y., and Kuroda, S. 1998. A robust increase in expression of arc gene, an effector immediate early gene, in the rat brain after acute and chronic methamphetamine administration. Brain Res. 796: 273-283.

Koh, M.T. and Bernstein, I.L. 2003. Inhibition of protein kinase A activity during conditioned taste aversion retrieval: Interference with extinction or reconsolidation of a memory? Neuroreport 14: 405-407.

Kraus, M., Schicknick, H., Wetzel, W., Ohl, F., Staak, S., and Tischmeyer, W. 2002. Memory consolidation for the discrimination of frequency-modulated tones in mongolian gerbils is sensitive to protein-synthesis inhibitors applied to the auditory cortex. Learn. Mem. 9: 293-303.

Lee, J.L., Everitt, B.J., and Thomas, K.L. 2004. Independent cellular processes for hippocampal memory consolidation and reconsolidation. Science 304: $839-843$.

Lee, J.L., Di Ciano, P., Thomas, K.L., and Everitt, B.J. 2005. Disrupting reconsolidation of drug memories reduces cocaine-seeking behavior. Neuron 47: 795-801.

Lee, J.L., Milton, A.L., and Everitt, B.J. 2006. Cue-induced cocaine seeking and relapse are reduced by disruption of drug memory reconsolidation. J. Neurosci. 26: 5881-5887.

Lim, G.P., Backstrom, J.R., Cullen, M.J., Miller, C.A., Atkinson, R.D., and Tokes, Z.A. 1996. Matrix metalloproteinases in the neocortex and spinal cord of amyotrophic lateral sclerosis patients. J. Neurochem. 67: 251-259.

Lochter, A., Galosy, S., Muschler, J., Freedman, N., Werb, Z., and Bissell, M.J. 1997. Matrix metalloproteinase stromelysin-1 triggers a cascade of molecular alterations that leads to stable epithelial-to-mesenchymal conversion and a premalignant phenotype in mammary epithelial cells. J. Cell Biol. 139: 1861-1872.

Lorenzl, S., Albers, D.S., Narr, S., Chirichigno, J., and Beal, M.F. 2002. Expression of MMP-2, MMP-9, and MMP-1 and their endogenous counterregulators TIMP-1 and TIMP-2 in postmortem brain tissue of Parkinson's disease. Exp. Neurol. 178: 13-20.

Ludwig, A.M., Wikler, A., and Stark, L.H. 1974. The first drink: Psychobiological aspects of craving. Arch. Gen. Psychiatry 30: $539-547$.

Mackowiak, M., Markowicz-Kula, K., Fijal, K., and Wedzony, K. 2005. Acute and repeated administration of cocaine differentially regulates expression of PSA-NCAM-positive neurons in the rat hippocampus. Brain Res. 1055: 149-155.

Massova, I., Kotra, L.P., Fridman, R., and Mobashery, S. 1998. Matrix metalloproteinases: Structures, evolution, and diversification. FASEB J. 12: 1075-1095.

McCawley, L.J. and Matrisian, L.M. 2001. Matrix metalloproteinases: They're not just for matrix anymore! Curr. Opin. Cell Biol. 13: $534-540$.

McFarland, K., Lapish, C.C., and Kalivas, P.W. 2003. Prefrontal glutamate release into the core of the nucleus accumbens mediates cocaine-induced reinstatement of drug-seeking behavior. J. Neurosci. 23: 3531-3537.

Meighan, S.E., Meighan, P.C., Choudhury, P., Davis, C.J., Olson, M.L., Zornes, P.A., Wright, J.W., and Harding, J.W. 2006. Effects of extracellular matrix-degrading proteases matrix metalloproteinases 3 and 9 on spatial learning and synaptic plasticity. J. Neurochem. 96: $1227-1241$.

Milekic, M.H., Brown, S.D., Castellini, C., and Alberini, C.M. 2006. Persistent disruption of an established morphine conditioned place preference. J. Neurosci. 26: 3010-3020.

Miller, C.A. and Marshall, J.F. 2005. Molecular substrates for retrieval and reconsolidation of cocaine-associated contextual memory. Neuron 47: 873-884.

Misanin, J.R., Miller, R.R., and Lewis, D.J. 1968. Retrograde amnesia produced by electroconvulsive shock after reactivation of a consolidated memory trace. Science 160: 554-555.

Mueller, D. and Stewart, J. 2000. Cocaine-induced conditioned place preference: reinstatement by priming injections of cocaine after extinction. Behav. Brain Res. 115: 39-47.

Nader, K. 2003. Memory traces unbound. Trends Neurosci. 26: 65-72.

\section{Learning \& Memory


Nader, K., Schafe, G.E., and Le Doux, J.E. 2000. Fear memories require protein synthesis in the amygdala for reconsolidation after retrieval. Nature 406: $722-726$.

Nagy, V., Bozdagi, O., Matynia, A., Balcerzyk, M., Okulski, P., Dzwonek, J., Costa, R.M., Silva, A.J., Kaczmarek, L., and Huntley, G.W. 2006. Matrix metalloproteinase-9 is required for hippocampal late-phase long-term potentiation and memory. J. Neurosci. 26: 1923-1934.

O'Brien, C.P., Childress, A.R., McLellan, A.T., and Ehrman, R. 1992. A learning model of addiction. Res. Publ. Assoc. Res. Nerv. Ment. Dis. 70: $157-177$

Odake, S., Morita, Y., Morikawa, T., Yoshida, N., Hori, H., and Nagai, Y. 1994. Inhibition of matrix metalloproteinases by peptidyl hydroxamic acids. Biochem. Biophys. Res. Commun. 199: 1442-1446.

Phillips, L.L. and Reeves, T.M. 2001. Interactive pathology following traumatic brain injury modifies hippocampal plasticity. Restor. Neurol. Neurosci. 19: 213-235.

Quartermain, D., Judge, M.E., and Jung, H. 1988. Amphetamine enhances retrieval following diverse sources of forgetting. Physiol. Behav. 43: 239-241.

Reeves, T.M., Prins, M.L., Zhu, J., Povlishock, J.T., and Phillips, L.L. 2003. Matrix metalloproteinase inhibition alters functional and structural correlates of deafferentation-induced sprouting in the dentate gyrus. J. Neurosci. 23: 10182-10189.

Riccio, D.C., Millin, P.M., and Bogart, A.R. 2006. Reconsolidation: A brief history, a retrieval view, and some recent issues. Learn. Mem. 13: $536-544$

Rivera, S., Ogier, C., Jourquin, J., Timsit, S., Szklarczyk, A.W., Miller, K., Gearing, A.J., Kaczmarek, L., and Khrestchatisky, M. 2002. Gelatinase $\mathrm{B}$ and TIMP-1 are regulated in a cell- and time-dependent manner in association with neuronal death and glial reactivity after global forebrain ischemia. Eur. J. Neurosci. 15: 19-32.

Robinson, T.E. and Kolb, B. 1997. Persistent structural modifications in nucleus accumbens and prefrontal cortex neurons produced by previous experience with amphetamine. J. Neurosci. 17: 8491-8497.

Robinson, T.E. and Kolb, B. 1999. Alterations in the morphology of dendrites and dendritic spines in the nucleus accumbens and prefrontal cortex following repeated treatment with amphetamine or cocaine. Eur. J. Neurosci. 11: 1598-1604.

Robinson, T.E. and Kolb, B. 2004. Structural plasticity associated with exposure to drugs of abuse. Neuropharmacology 47 (Suppl. 1): $33-46$.

Robinson, T.E., Gorny, G., Mitton, E., and Kolb, B. 2001. Cocaine self-administration alters the morphology of dendrites and dendritic spines in the nucleus accumbens and neocortex. Synapse 39: 257-266.

Salinska, E., Bourne, R.C., and Rose, S.P. 2004. Reminder effects: The molecular cascade following a reminder in young chicks does not recapitulate that following training on a passive avoidance task. Eur. J. Neurosci. 19: 3042-3047.

Sangha, S., Scheibenstock, A., Morrow, R., and Lukowiak, K. 2003. Extinction requires new RNA and protein synthesis and the soma of the cell right pedal dorsal 1 in Lymnaea stagnalis. J. Neurosci. 23: 9842-9851.

Sara, S.J. 2000. Retrieval and reconsolidation: Toward a neurobiology of remembering. Learn. Mem. 7: 73-84.

Schmidt, H.D. and Pierce, R.C. 2006. Cooperative activation of D1-like and D2-like dopamine receptors in the nucleus accumbens shell is required for the reinstatement of cocaine-seeking behavior in the rat. Neuroscience 142: 451-461.

Shaham, Y., Shalev, U., Lu, L., De Wit, H., and Stewart, J. 2003. The reinstatement model of drug relapse: History, methodology and major findings. Psychopharmacology 168: 3-20.

Somerville, R.P., Oblander, S.A., and Apte, S.S. 2003. Matrix metalloproteinases: Old dogs with new tricks. Genome Biol. 4: 216.

Stamenkovic, I. 2003. Extracellular matrix remodelling: The role of matrix metalloproteinases. J. Pathol. 200: 448-464.

Tan, A., Moratalla, R., Lyford, G.L., Worley, P., and Graybiel, A.M. 2000. The activity-regulated cytoskeletal-associated protein arc is expressed in different striosome-matrix patterns following exposure to amphetamine and cocaine. J. Neurochem. 74: 2074-2078.

Thomas, M.J., Malenka, R.C., and Bonci, A. 2000. Modulation of long-term depression by dopamine in the mesolimbic system. $J$. Neurosci. 20: 5581-5586.

Tronel, S. and Sara, S.J. 2002. Mapping of olfactory memory circuits: Region-specific c-fos activation after odor-reward associative learning or after its retrieval. Learn. Mem. 9: 105-111.

Ujike, H. 2002. [Molecular biology of drug dependence and behavioral sensitization]. Seishin Shinkeigaku Zasshi 104: 1055-1068.

Valjent, E., Corbille, A.G., Bertran-Gonzalez, J., Herve, D., and Girault, J.A. 2006. Inhibition of ERK pathway or protein synthesis during reexposure to drugs of abuse erases previously learned place preference. Proc. Natl. Acad. Sci. 103: 2932-2937.

Vianna, M.R., Szapiro, G., McGaugh, J.L., Medina, J.H., and Izquierdo, I. 2001. Retrieval of memory for fear-motivated training initiates extinction requiring protein synthesis in the rat hippocampus. Proc. Natl. Acad. Sci. 98: 12251-12254.

Wise, R.A. 2000. Addiction becomes a brain disease. Neuron 26: 27-33.

Wright, J.W. and Harding, J.W. 2004. The brain angiotensin system and extracellular matrix molecules in neural plasticity, learning, and memory. Prog. Neurobiol. 72: 263-293.

Wright, J.W., Masino, A.J., Reichert, J.R., Turner, G.D., Meighan, S.E., Meighan, P.C., and Harding, J.W. 2003. Ethanol-induced impairment of spatial memory and brain matrix metalloproteinases. Brain Res. 963: 252-261.

Yim, A.J., Moraes, C.R., Ferreira, T.L., and Oliveira, M.G. 2006. Protein synthesis inhibition in the basolateral amygdala following retrieval does not impair expression of morphine-associated conditioned place preference. Behav. Brain Res. 171: 162-169.

Zhang, J.W., Deb, S., and Gottschall, P.E. 1998. Regional and differential expression of gelatinases in rat brain after systemic kainic acid or bicuculline administration. Eur. J. Neurosci. 10: 3358-3368.

Zhang, J.W., Deb, S., and Gottschall, P.E. 2000. Regional and age-related expression of gelatinases in the brains of young and old rats after treatment with kainic acid. Neurosci. Lett. 295: 9-12.

Received November 15, 2006; accepted in revised form December 19, 2006. 


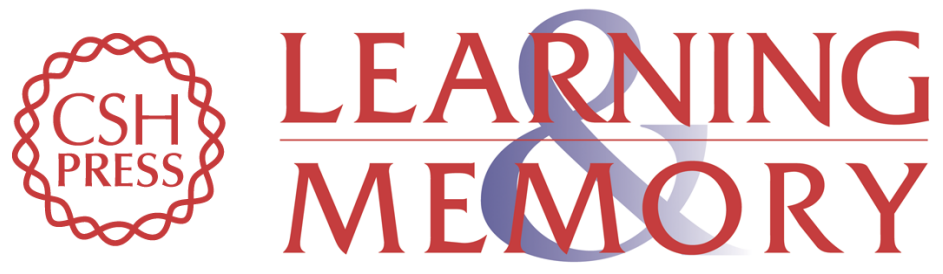

\section{Role of matrix metalloproteinases in the acquisition and reconsolidation of cocaine-induced conditioned place preference}

Travis E. Brown, Melissa R. Forquer, Davelle L. Cocking, et al.

Learn. Mem. 2007, 14:

Access the most recent version at doi:10.1101//m.476207

References This article cites 73 articles, 23 of which can be accessed free at:

http://learnmem.cshlp.org/content/14/3/214.full.html\#ref-list-1

License

Email Alerting Receive free email alerts when new articles cite this article - sign up in the box at the Service top right corner of the article or click here. 